\title{
A Glow Discharge Ion Source with Fourier Transform Ion Cyclotron Resonance Mass Spectrometric Detection
}

\author{
Christopher M. Barshick and John R. Eyler \\ Department of Chemistry, University of Florida, Gainesville, Florida, USA
}

\begin{abstract}
A glow discharge (GD) ion source has been coupled to a Fourier transform ion cyclotron resonance (FT-ICR) mass spectrometer using a four-element electrostatic lens to accelerate and focus ions generated external to the instrument's high magnetic field into its analyzer cell. Like other GD mass spectrometers, GD-FT-ICR can provide a quantitative measure of bulk analyte concentration with good precision and accuracy. Although detection limits currently attainable are several orders of magnitude higher than the commercially available magnetic sector-based instrument, GD-FT-ICR holds promise for ultrahigh resolving power elemental mass analysis. Several schemes are proposed to lower the detection limits of the technique while still providing high enough resolution to resolve isobaric interferences. () Am Soc Mass Spectrom 1992, 3, 122-127)
\end{abstract}

$\mathrm{T}$ lechniques of Fourier transform ion cyclotron resonance (FT-ICR) mass spectrometry [1-4] have been applied to a wide range of chemical problems, from ion photodissociation [5-7] to comparisons of gas-phase and solution reactivity $[8,9]$ to analyses of polymers and biopolymers [10-12]. With the exception of conventional electron impact ionization, laser desorption (LD) ionization has been the most widely applied means of ion formation in FT-ICR experiments [13-15]. However, the susceptibility of many compounds to physical damage induced by LD has imposed an inherent limitation on LD-FT-ICR use and has prevented its widespread acceptance. Concurrently, other ionization methods, such as fast-atom bombardment or supersonic expansion/photoionization, have proven difficult to implement because the relatively high background pressures accompanying them are not compatible with ultrahigh mass/ultrahigh resolution FT-ICR analysis.

Efforts to reduce the effects of high pressures from alternative ionization sources have involved two different approaches. The first makes use of a dual cell configuration [16], in which ion formation takes place in a high pressure source region, with ions subsequently transferred through a small conductance limit to a lower pressure analysis region. In the second approach, the ions are generated in a region external to the magnetic field associated with the FT-ICR experiment, and are then injected into the analyzer cell

Address reprint requests to John R. Eyler, Department of Chemistry, University of Florida, Gainesville, FL 32611-2046. through several stages of differential pumping. Successful external ion generation followed by FT-ICR analysis was first reported by Mclver et al. [17]. They employed a radiofrequency-only quadrupole ion guide to transport ions from a high pressure external ion source into an ICR cell maintained at several orders of magnitude lower pressure; there the ions were trapped and mass analyzed. Several other groups [18-23] have used this or other approaches not involving quadrupoles to transport ions generated by a variety of alternative ionization sources into FT-ICR analyzer cells.

One means of external ionization that has not yet been used with FT-ICR mass spectrometers is the glow discharge (GD): a type of gaseous plasma, as exemplified by a common neon light. The glow discharge, whose name arises from the bright central glow produced by the emission from excited gaseous atoms, is a partially ionized gas consisting of an equal number of positively and negatively charged species and a larger number of neutral species [24]. The source consists of two electrodes typically operating in a low pressure (0.1-10 torr) rare gas environment. A representative analyte population is produced by cathodic sputtering, and the atoms are subsequently excited and ionized in the negative glow region of the discharge.

Glow discharge mass spectrometry (GDMS) combines the design simplicity of the GD ion source with the high sensitivity and selectivity of mass spectrometric analysis [25-27]. The GD is often compared with a better known plasma source, the inductively 
coupled plasma (ICP). While the spectral complexity of GDMS and ICP-MS are comparable, GDMS has better precision when sampling solids directly, and the ICP has better limits of detection when used with a comparable mass analyzer [28]. The GD ion source is compact and relatively inexpensive to build and maintain, and it operates at modest gas consumption rates (milliliters per minute) and low wattage. Specific analytical problems have arisen, however, where more versatility than provided by commercially available instrumentation is necessary. Radiofrequency discharges have been coupled to quadrupole and magnetic sector instrumentation to analyze nonconducting samples, and a thermal atomizer has been fitted on a quadrupole for solution analysis [29]. In addition, other efforts have utilized conventional direct current GD as sources for more specialized mass analyzers [30]. We report in this article the successful coupling of a GD ion source to an FT-ICR mass spectrometer. The results of initial experiments are presented, and possible applications based on the high mass resolution provided by FT-ICR mass analysis are discussed.

\section{Experimental}

The positive ions generated in the negative glow region of a coaxial cathode GD were mass analyzed by a home-built FT-ICR mass spectrometer described in more detail elsewhere [31]. The instrument employed a Nicolet FTMS-1000 (now sold by Extrel, Madison, WI) electronics console to control a $2.54 \times 2.54 \times$ $4.50-\mathrm{cm}$ ( $z$-axis) ion analyzer cell. Figure 1 illustrates modifications necessary to interface the FT-ICR mass spectrometer to the GD source. A 1-in. Cajon Tee
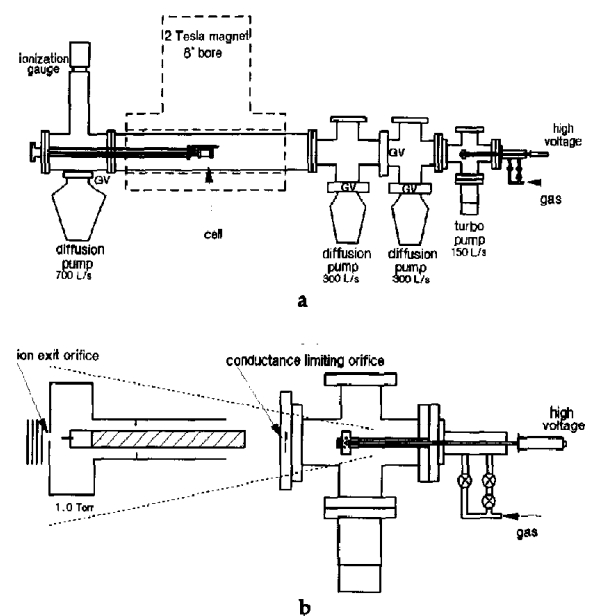

Figure 1. (a) A 2-T FT-ICR mass spectrometer modified to accommodate a $\mathrm{CD}$ ion source. (b) An expanded view of a showing the GD ion source region in detail.
(Cajon Company, Macedonia, $\mathrm{OH}$ ) served as the housing for the GD, which was formed about a machined $2.0-\mathrm{mm}$ diameter pin cathode positioned on the end of a direct insertion probe for manipulation in the high vacuum system. The GD was operated with a constant current of $2.0 \mathrm{~mA}$ at $1500 \mathrm{~V} \mathrm{dc}$. A cathodeto-anode separation distance of between 10 and 13 $\mathrm{mm}$ was used at a discharge pressure of 1.0 torr argon, and the sample was presputtered for $30 \mathrm{~min}$ to remove surface contaminants.

The ion injection method was similar to the approach of Kofel et al. [18], in that no quadrupole ion guide was used to focus and transport ions into the cell. Instead, a series of four ring electrodes, $2.54 \mathrm{~mm}$ long $\times 12.70 \mathrm{~mm}$ in diameter, with a $1.59-\mathrm{mm}$ wall, accelerated and focused ions sampled from a $1.0-\mathrm{mm}$ diameter ion exit orifice. Teflon spacers were machined to the same dimensions as the ring electrodes and served to isolate each lens, floated with a potential between ground and $-1000 \mathrm{~V}$ dc. The first element was maintained near $-1000 \mathrm{~V} d c$ to accelerate the ions from ground, whereas lenses 2-4 were varied to obtain a maximum ion signal from the sputtered species. One exemplary combination was: lens 1 $-1000 \mathrm{~V}$, lens $2-10 \mathrm{~V}$, lens $3-614 \mathrm{~V}$, and lens 4 $-761 \mathrm{~V}$.

In these initial studies only one stage of differential pumping was employed, facilitating the need for a $150 \mathrm{~L} / \mathrm{s}$ turbomolecular pump at the ion source, in tandem with two $300-\mathrm{L} / \mathrm{s}$ and one $700-\mathrm{L} / \mathrm{s}$ diffusion pumps at the analyzer. In this manner the analyzer pressure could be maintained at $2 \times 10^{-6}$ torr (discharge pressure $=1.0$ torr). To obtain higher resolution mass spectra, the collision frequency in the ion cell was further reduced by placing a second $1.0-\mathrm{mm}$ diameter orifice between the electrostatic lenses and the FT-ICR analyzer cell (Figure 1b). In this configuration the analyzer could be maintained at $9 \times 10^{-8}$ torr, but with a reduction to one-third of the original signal intensity.

A typical pulse sequence involved dropping the analyzer cell trapping plates from $+2 \mathrm{~V}$ to ground for a period of $0.1-5.0 \mathrm{~s}$ to allow ions to be "injected" into the cell, and then raising the plates back to $+2 \mathrm{~V}$ for the detection phase. In order to obtain optimum sensitivity, ions at $m / z 18,19,20,28,29,40$, and 41 $\left(\mathrm{H}_{2} \mathrm{O}^{+}, \mathrm{H}_{3} \mathrm{O}^{+}, \mathrm{Ar}^{+2}, \mathrm{~N}_{2}^{+}, \mathrm{N}_{2} \mathrm{H}^{+}, \mathrm{Ar}^{+}\right.$, and $\mathrm{ArH}^{+}$, respectively) were selectively ejected from the cell via a swept frequency ejection pulse. In typical experiments ions with frequencies from $10 \mathrm{kHz}$ to 2.667 $\mathrm{MHz}$ were excited and detected with a bandwidth of $2.667 \mathrm{MHz}$. Fifty time domain signals of $16 \mathrm{~K}$ data points each were accumulated, and the average time domain signal was apodized by a modified Blackman-Harris window function [32] and zero-filled once prior to Fourier transformation. For higher resolution analysis, fifty time domain signals of $64 \mathrm{~K}$ data points each were averaged, and a standard heterodyne approach was employed [2]. 


\section{Results and Discussion}

\section{GD-FT-ICR Mass Spectra}

Figure 2 shows the mass spectrum obtained when a $\mathrm{Cu}$ pin was used as the cathode in an argon discharge. The copper isotopes at $m / z 63$ and 65 are the major peaks, along with "interference" peaks from $\mathrm{ArH}^{+}$, formed from trace levels of water in the argon discharge gas and $\mathrm{Ar}^{+}$. Isotopic ratios agree with known values to $\sim \pm 0.25 \%$. Figure 3 shows the results obtained for a National Institute of Standards and Technology (NIST) stainless steel sample, 1261a, with the $\mathrm{Ar}^{+}$and $\mathrm{ArH}^{+}$ions ejected. Interfering peaks at mass $18,19,28$, and 29 result from $\mathrm{H}_{2} \mathrm{O}^{+}, \mathrm{H}_{3} \mathrm{O}^{+}$, $\mathrm{N}_{2}^{+}$, and $\mathrm{N}_{2} \mathrm{H}^{+}$, respectively. Minor components of the sample at the $0.5-2 \%$ level are easily detected, and the isotopic ratios agree with known values to $\sim \pm 5 \%$.

\section{Detection Limits}

The detection limit for nickel in an NIST 1261a standard reference material was calculated for 50 scans accumulated over a 10-100 u mass range. The standard deviation of the mean [33] for five background measurements was 15,090 counts. The ${ }^{60} \mathrm{Ni}$ isotope, present at $0.52 \%$ in Figure 3 , yielded an ion signal of 3.5 million counts, and the detection limit, calculated by multiplying the inverse of the sensitivity (1.5 $\mathrm{ppt} /$ count) by three times the mean standard deviation of the background [34], was $70 \mathrm{ppm}$. The value is rather high when compared with other GDMS instruments, for which the detection limits are on the order of 1 part in 1 billion for magnetic sector instruments and 1 part in 1 million for the quadrupole GDMS [35]. However, improvements in our relatively simple ion injection scheme (for instance the addition of a quadrupole ion guide) should lower the limit of detection by several orders of magnitude.

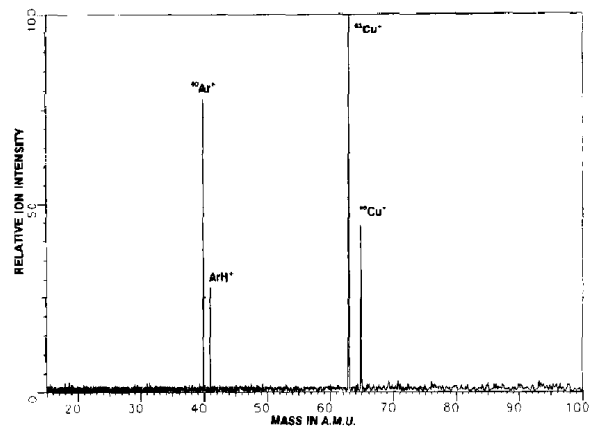

Figure 2. Low resolution GD-FT-ICR mass spectrum of a copper cathode. 1.0 torr argon; $1500 \mathrm{~V}$ dc discharge.

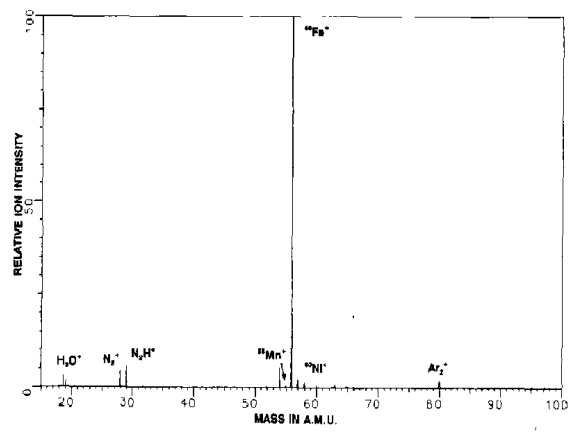

Figure 3. Low resolution GD-FI-ICR mass spectrum of an NIST 1261a stainless steel cathode. 1.0 torr argon; $1500 \mathrm{~V} \mathrm{dc}$ discharge; ${ }^{40} \mathrm{Ar}^{+}$and $\mathrm{ArH}^{+}$ejected.

\section{Quantitative Analysis}

One of the main advantages of GDMS analysis is its ability to provide a quantitative measurement of analyte concentration. It is common in elemental mass spectrometry to employ a reference sample and normalization factors to correct for the sensitivity variations from element to element. These relative sensitivity factors (RSF) have been shown to depend upon the discharge conditions (pressure, current, etc.), as well as the source geometry and the ion optics [36, 37], and are usually evaluated prior to analysis. The RSF value can be calculated from a standard sample by the relationship:

$$
\operatorname{RSF}_{x}=\left(I_{r} / C_{r}\right) /\left(I_{x} / C_{x}\right)
$$

where $I_{x}$ is the signal intensity for species $x$ at a known concentration $C_{x}$, and $I_{r}$ is the signal intensity of the reference $r$, at a known concentration $C_{r}$. The RSF value is then used as the normalization factor in conjunction with an internal standard of the reference species for the analysis of an unknown analyte ion of species $x$ in a different sample. Because peak area has been shown to be superior to peak height for measuring relative abundances in FT-ICR [38], all quantitative measurements incorporated peak area values.

The RSF values of ${ }^{60} \mathrm{Ni}$ and ${ }^{52} \mathrm{Cr}$ for an NIST $1263 \mathrm{a}$ stainless steel sample were calculated relative to the concentration of ${ }^{55} \mathrm{Mn}$ as the reference from data obtained for ten repetitive trials of 50 scans each. For the ${ }^{60} \mathrm{Ni}$ and ${ }^{52} \mathrm{Cr}$ species the mean RSF values were 2.34 and 1.13 , with a standard deviation of the mean of the ten trials being \pm 0.12 and \pm 0.02 , respectively. These values compare well with RSFs obtained using quadrupole and magnetic sector instruments [36, 37], where RSFs generally range between 1 and 10 . The calculated RSF values were then used to determine the concentration of nickel and chromium in a differ- 
ent stainless steel sample (NIST 1261a) by:

$$
C_{x}^{\prime}=\left(\operatorname{RSF}_{x}\right)\left[\left(I_{x}^{\prime}\right)\left(C_{\mathrm{r}}\right) /\left(I_{\mathrm{r}}\right)\right]
$$

Table 1 lists the certified concentrations, as well as the concentrations calculated with the RSF values and those calculated by direct ratioing of the peak areas (i.e., by assuming RSFs of unity). For both analytes, the application of the RSF value improved the accuracy of the analysis and produced an error comparable with literature values [39].

\section{Polyatomic Interferences}

Isobaric interferences have been shown to be a universal problem in elemental mass spectrometry, regardless of ion source type. In the GD, isobaric interferences arise from several sources including overlapping isotopes, doubly charged species, and polyatomic ions. This last category is the most common, with interfering species originating from (1) ionized vacuum system impurities, (2) ionized sputtered polyatomic species, and (3) polyatomic ions generated by ion/molecule reactions.

Two schemes have been proposed to overcome isobaric interferences: discrimination and suppression/elimination [36]. The first of these, discrimination, is the approach used when the GD source is coupled to a high resolution magnetic sector mass spectrometer. Some typical diatomic ion interferences are dimers, oxides, and argides. The required resolution necessary to effect separation of these species from an analyte of the same nominal mass varies from a few thousand to an excess of 60,000 [36]. It should be noted that at present the commercial magnetic sector instrument has resolution of $\sim 10,000$ and would only be able to effect separation of a fraction of these species.

The second method, first reported by King and Harrison [30], involves elimination of glow discharge polyatomic species by collision induced dissociation (CID) in the radiofrequency-only section of a triple stage quadrupole (TSQ). Rowan and Houk [40] performed similar experiments on an ICP using a double quadrupole. Elimination should be a more effective approach to the problem of isobaric interferences, because the need for ultrahigh resolution is no longer a factor. However, several limitations of this ap-

Table 1. Concentrations in an NIST 1261a standard reference sample

\begin{tabular}{lccc}
\hline Isotope & $\begin{array}{c}\text { Certified } \\
(\%)\end{array}$ & $\begin{array}{c}\text { Without RSF } \\
(\%)\end{array}$ & $\begin{array}{c}\text { With RSF } \\
(\%)\end{array}$ \\
\hline${ }^{55} \mathrm{Mn}$ & $0.66 \pm 0.01$ & - & - \\
${ }^{52} \mathrm{Cr}$ & $0.58 \pm 0.01$ & $0.49 \pm 0.01$ & $0.55 \pm 0.02$ \\
${ }^{60} \mathrm{Ni}$ & 0.52 & $0.25 \pm 0.01$ & $0.58 \pm 0.03$ \\
\hline
\end{tabular}

${ }^{a}$ RSF values obtained from the analysis of an NIST 1263a standard reference sample (see text). proach, most notably the scattering loss of $\mathrm{M}^{+}$and the spread of kinetic energies of the product ions, have prevented it from gaining commercial success.

The FTMS approach holds the potential for both discrimination (with ultrahigh resolving power) and elimination (with a greater probability for collisional dissociation than the TSQ approach because the trapped ions can undergo multiple collisions [2]) of isobaric interferences. In a series of precursory studies, moderate resolution mass spectra were generated from a brass cathode in an argon discharge. Figure $4 a$ illustrates the 39.5-41.5-u region of the spectrum with $\mathrm{Ar}^{+}$and $\mathrm{ArH}^{+}$indicated at nominal masses of 40 and 41. The observed resolution for $\mathrm{Ar}^{+}$is 6158 at fullwidth half maximum. Figure $4 \mathrm{~b}$ shows the copper and zinc species in the mass range $62-67 \mathrm{u}$; the ${ }^{63} \mathrm{Cu}{ }^{+}$ion has resolution of 7696 .

To demonstrate the high resolution advantage of GD-FT-ICR for solving the problem of isobaric interferences, a test cathode consisting of $2.0 \mathrm{~g}$ of $99.999 \%$ tantalum, $0.2 \mathrm{~g}$ of $99.99 \%$ cerium oxide, and $0.2 \mathrm{~g}$ of $99.99 \%$ gadolinium oxide was prepared in the shape of a $4.5 \mathrm{~mm}$ diameter disk cathode. In Figure $5 \mathrm{a}$ the
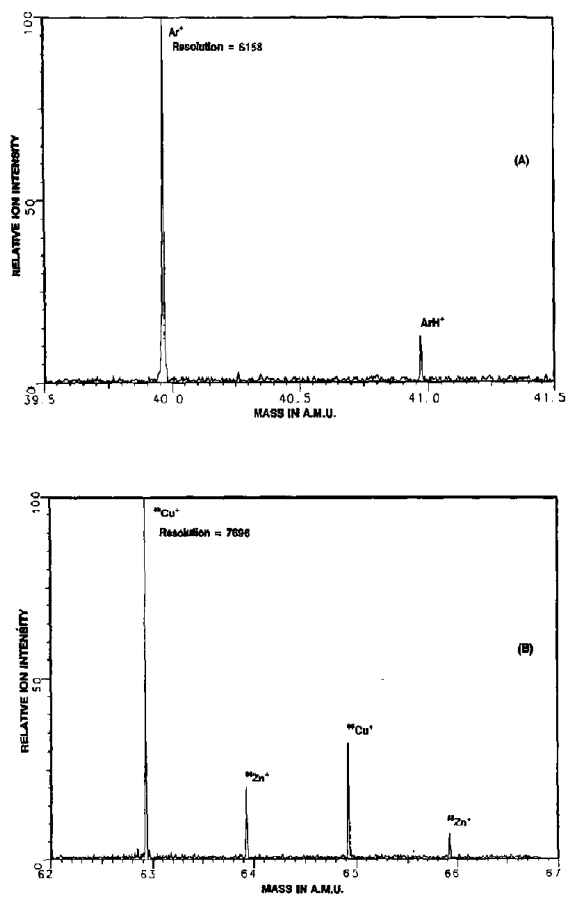

Figure 4. (a) Moderate resolution GD.FT-ICR mass spectrum of a brass cathode in the mass range 39.5-41.5 $\mathrm{u} ; \mathrm{m} / \Delta \mathrm{M}=6158$ at nominal mass ${ }^{40} \mathrm{Ar}^{+}$. (b) Moderate resolution GD-FT-ICR spectrum of a brass cathode in the mass range 62-67 $\mathrm{u} ; \mathrm{m} / \Delta \mathrm{m}$ $=7696$ at nominal mass ${ }^{63} \mathrm{Cu}^{+} .1 .5$ torr argon; $1000 \mathrm{~V}$ dc discharge. 
135-170-u region of the mass spectrum from this sample shows peaks due to both cerium and gadolinium. However, the isotope at mass 156 is larger than anticipated for a pure ${ }^{156} \mathrm{Gd}^{+}$constituent; this result is indicative of an isobaric interferant, presumably $\mathrm{CeO}^{+}$(also with nominal mass 156 ). Figure $5 \mathrm{~b}$ shows the 155.5-158.5-u region of the mass spectrum with higher resolution due to acquisition using a standard heterodyne approach [2]. It is clear that with the $>7000$ resolution obtainable, the $\mathrm{CeO}^{+}$constituent is resolved from the ${ }^{156} \mathrm{Gd}^{+}$analyte of interest. Isotopic ratios of the three gadolinium peaks shown in Figure $5 \mathrm{~b}$ are within $10 \%$ of accepted values, giving further confidence in this result.

To date, the highest resolution obtained with GDFT-ICR has been for an ${ }^{40} \mathrm{Ar}^{+}$ion: $m / \Delta m=41,056$. Although these results are preliminary, they demonstrate the possibility of ultrahigh resolution GDMS. Studies are continuing to exploit the unique capabilities of the FT-ICR technique to resolve/eliminate GD isobaric interferences.
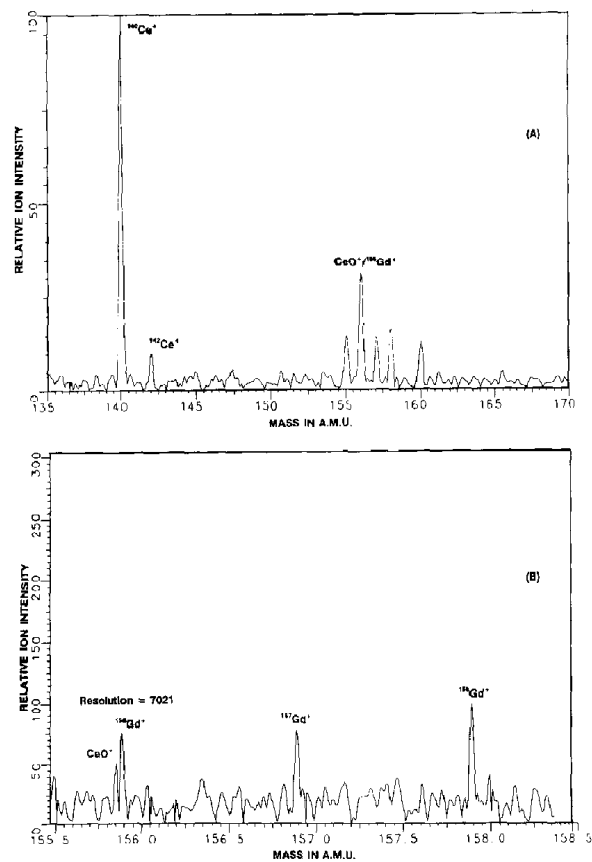

Figure 5. (a) Moderate resolution GD-FT-ICR mass spectrum of a compressed cathode consisting of $2.0 \mathrm{~g}$ of $99.999 \%$ tanta$\operatorname{lum} / 0.2 \mathrm{~g}$ of $99.99 \%$ cerium oxide $/ 0.2 \mathrm{~g}$ of $99.99 \%$ gadolinium oxide in the mass range $135-170 \mathrm{u}$. (b) Moderate resolution GD-FT-ICR mass spectrum of the tantalum/cerium oxide/gadolinium oxide cathode of part $\mathbf{a}$ in the mass range 155.5-158.5 $\mathrm{u}_{\mathrm{i}}$ $m / \Delta m=7021$ at nominal mass ${ }^{156} \mathrm{Gd}^{+} .1 .5$ torr argon; $1000 \mathrm{~V}$ dc discharge.

\section{Conclusions}

A GD ion source has been successfully interfaced to an FT-ICR mass spectrometer. Preliminary results indicate detection limits are on the order of $70 \mathrm{ppm}$, and that improved limits of detection will result from increasing the ion throughput, while simultaneously reducing the analyzer pressure. Quantitative analysis at the $0.5 \%$ level has been demonstrated through the use of NIST standard reference materials and relative sensitivity factors to account for sputtering and ionization differences between different elements in various materials. Moderate resolution of $m / \Delta m \approx 10,000$ and high resolution of $m / \Delta m \approx 40,000$ indicate that GD-FT-ICR holds the potential for solving the problem of isobaric interferences in elemental mass spectrometry.

\section{Acknowledgments}

We acknowledge Willard Harrison for the loan of various items of equipment associated with the glow discharge, K. R. Williams for numerous helpful comments, and the Office of Naval Research for partial support of this research.

\section{References}

1. Baykut, G.; Eyler, J. R. Trends Anal. Chem. 1986, 5, 44

2. Buchanan, M. V.; Comisarow, M. B. In Fourier Transform Mass Spectrometry: Evolution, Innovation, and Applications, ACS Symp. Ser.; Buchanan, M. V., Ed.; American Chemical Society: Washington, $1987 ; 359$, p 1.

3. Wilkins, C. L.; Chowdhury, A. K.; Nuwaysir, L. M.; Coates, M. L. Mass Spectrom. Rev. 1989, 8, 67.

4. Marshall, A. G.; Grosshans, P. B. Anal. Chem. 1991, 63, 215A.

5. Thorne, R. L.; Beauchamp, J. L. In Gas Phase Ion Chemistry, Vol 3; Bowers, M. T., Ed.; Academic: New York, 1984; p 41.

6. Dunbar, R. C. In Gas Phase Ion Chemistry, Vol 3; Bowers, M. T., Ed.; Academic: New York, 1984; p 129

7. Baykut, G; Watson, C. H.; Weller, R. R.; Eyler, J. R. J. Am. Chem. Soc. 1985, 107, 8036.

8. Wolf, J. F.; Staley, R. H.; Koppel, I.; Taagepera, M.; McIver. R. T.; Beauchamp, J. L.; Taft, R. W. I. Am. Chem. Soc. 1977, 99,5417 .

9. Richardson, D. E. Inorg. Chem. 1990, 29, 3213.

10. Russell, D. H.: Castro, M. E. In Mass Spectrometry in Biomedical Research; Gaskel, 5. J., Ed.; J. Wiley \& Sons: New York, 1986; $\mathrm{p} 313$.

11. Ijames, C. F.; Wilkins, C. L. J. Am. Chem. Soc. 1988, 110, 2687.

12. Brown, C. E.; Kovacic, P.; Welch, K. J.; Cody, R. B.; Hein, R. E.; Kinsinger, J. A. Arabian J. Sci. Eng. 1988, 13, 163.

13. MeCrery, D. A.; Ledford, E. B., Jr.: Gross, M. L. Anal. Chem, 1982, 54, 1435.

14. Wilkins, C. L.; Weil, D. A.; Yang, C. L. C.; ljames, C. F Anal. Chem. 1985, 47, 520.

15. Watson, C. H.; Baykut, G.; Eyler, J. R. Anal, Chem. 1987, $59,1133$.

16. Cody, R. B.; Kinsinger, I. A. In Fourier Transform Mass Spectrometry: Evolution, Innovation, and Applications, ACS Symp. Ser.; Buchanan, M. V., Ed.; American Chemical Society: Washington, 1987; 359, p 59 
17. McIver, R. T., Jr.; Hunter, R. L.; Bowers, W. D. Int. I. Mass Spectrom. Ion Processes 1985, 64, 67.

18. Kofel, P.; Alleman, M.; Kellerhals, H.; Wanczek, K. P. Int. J. Mass. Spectrom. Ion Processes 1985, 65, 97.

19. Alford, J, M,; Williams, P. E.; Trevor, D. J.; Smalley, R. E. Int. J. Mass. Spectrom. Ion Processes 1986, 72, 33.

20. Hunt, D. F.; Shabanowitz, J.; Yates, J. R.; Zhu, N. Z.; Russell, D. H.; Castro, M. E. Proc. Natl. Acad. Sci. U.S.A. $1987,84,620$.

21. Jjames, C. F.; Wilkins, C. L. J. Am. Soc. Mass, Spectrom. $1990,1,208$.

22. Henry, K. D.; McLafferty, F. W. Org. Mass Spectrom. 1990, 25,490 .

23. Kofel, P.; McMahon, T. B. Int. J. Mass. Spectrom. Ion Processes 1990, 98, 1.

24. Chapman, B. Glow Discharge Processes, Sputtering and Plasma Etching, John Wiley \& Sons: New York, 1980; Chapter 3.

25. Sanderson, N. E.; Hall, E.; Clark, J.; Charalambous, P.; Hall, D. Mikrochim. Acta 1987 l, 275.

26. Harrison, W. W, Bentz, B. L. Prog. Anal. Spectrosc. 1988, $11,53$.

27. Harrison, W. W.; Barshick, C. M.; Klingler, J. A.; Ratliff, P. H.; Mei, Y. Anal. Chem. 1990, 62, 943A

28. Horlick, G. Presented at 1990 Winter Conference on Plasma
Spectrochemistry, St. Petersburg, FL, January, 1990. [Abstract No. PL5]

29. Duckworth, D. C.; Marcus, R. K.; Christie, W. H.; Donohue, D. L.; Smith, D. H. 38th ASMS Conference on Mass Spectrometry and Allied Topics, Tucson, Arizona, June, 1990 [Proceedings P 393]. Ratliff, P. H; Harrison, W. W. 38th ASMS Conference on Mass Spectrometry and Allied Topics, Tucson, Arizona, June, 1990 [Proceedings p 1441].

30. King. F. L.; Harrison, W. W. Int. J. Mass Spectrom. Ion Proc. $1989,89,171$.

31. Zimmerman, J. A.; Bach, S. B. H.; Watson, C. H.; Eyler, J. R. J. Phys. Chem. 1991, 95, 98.

32. Harris, F. J. Proc. IEEE 1978, 66, 51.

33. Shoemaker, D. P.; Garland, C. W.; Steinfeld, J. I.; Nibler, J. W. Experiments in Physical Chemistry; McGraw-Hill: New York, 1981; p 725.

34. Long, G. L.; Winefordner, J, D. Anal, Chem. 1983, 55, 712A.

35. Cantle, J. E.; Hall, E. F.; Shaw, C. J.; Turner, P. J. Int. I. Mass Spectrom. Ion Phys. 1983, 46, 11.

36. King, F. L. Ph.D. Dissertation; University of Virginia, 1989.

37. Vieth, W.; Huneke, J. C. Spectrochim. Acta 1991, 46B, 137.

38. Liang, Z.; Marshall, A. G. Anal. Chem. 1990, 62, 70.

39. Taylor, W. S.; Dulak, J. C. Spectroscopy 1989, 4, 41.

40. Rowan, J. T.; Houk, R. S. Appl. Spectrosc. 1989, 43, 976. 